\title{
ILUSTRACION EN ESPAÑA Y AMERICA \\ (Ensayo sobre una coyuntura renovadora)*
}

Pedro A. Vives Azancot**

No escapa a estas alturas a ningún historiador americanista que el movimiento cultural de la Ilustración, aquella larga onda expansiva de ideas y actitudes hacia el progreso en el siglo XVIII, alcanzó cotas insospechadas de transcendencia para todos los ámbitos hispánicos entre aproximadamente $1750 / 60$ y $1810 / 20$ cuando menos. Tal marco cronológico es el que en este breve ensayo ponderativo se entiende como etapa renovadora para España y América hispánica. Etapa renovadora, precisamente, por estar impregnada en su dilatado desarrollo de la articulación eideética que la revolución científica, que conocemos con la expresión genérica de "Ilustración", proyectó sobre hombres y estados, sobre ciudades y regiones, a ambos lados del Atlántico.

No es ni mucho menos anecdótico, como bien sabemos, que tal proceso renovador coincidiera pelanamente con el reinado de Carlos III. Pero se hace necesario a menudo, si de enmarcar la Ilustración española y americana se trata, plantear siquiera las claves básicas de aquel reinado que entre 1759 y 1788 fue capaz de remover algunas estructuras anquilosadas, transferir la necesidad vital y política de progreso en la mayoría de sus reinos y, especialmente para América, abrir el camino irreversible hacia la "modernidad". Parece claro en nuestros días que la propria metrópoli española conoció ya a fines del siglo XVII el primer viento renovador de carácter científico, desde la aparición en 1786 de la Carta filosófico-médico chymica de Juan de Cabriada; la propia América española conoció los apuntes de una nueva era a través del mexicano Sigüenza y Gôngora, casi antes de que pudiera soñarse con un "siglo de las Luces". Y puede asegurar-se también hoy la imparable coyuntura de crecimiento económico, y específicamente de expansión comercial, que afectó a los distintos mundos coloniales americanos entre 1680 y 1745 , como fechas de referencia elemental. 
En cualquier caso, aunque quepa de tectar avances innovadores, chispazos prematuros quizá, o precedentes más o menos claros de lo que Charles Morazé ha explicado como apertura de un dominio de lo cerebral sobre lo emotivo en la concepción de lo imaginario ${ }^{1}$ en los ámbitos hispánicos las "luces" tuvieron que esperar a que la infraestructura política y administrativa del estado de la monarquía borbónica provocara la eclosión de ideas nuevas entre estructuras arcaizantes. Tal infraestructura a la que me acabo de referir no fue posible en tanto la monarquía no se desligó de conflictos heredados del pasado; conflictos nacidos de la decadencia del Estado de los Austrias, de las ligaduras diplomáticas, económicas y estratégicas fraguadas en Utrecht en 1713; conflictos para el estado del primer Borbón español que mantuvieron a su monarquía estancada en la contención de luchas hegemónicas por el Atlántico - y muy concretamente por el Caribe -, y limitados sus visos de cambio in temo a la reforma de la estructura burocrática y a la forzada revisión de la unidad de la Monarquía. Ciertamente, ambos frentes de transformación interna acabaron siendo capitales para el futuro de la España ilustrada. Pero más cierto aún que en tanto esa dinámica de conflictos hegemónicos no fue rota por la decidida búsqueda de la paz, la Ilustración - la revolución científica capaz de hacer de la razón la herramienta de lo imaginario - no tuvo ocasión de impregnar la realidad de España y de sus tierras americanas.

Hay por tanto que emplazar en el reinado de Fernando VI el arranque de la Ilustración hispánica en sus plenas y profundas expresiones; especialmente a partir de la liquiidación por la Paz de Aquisgrán, en 1748, de los viejos sistemas de conflicto estratégico. Y justamente a partir de esos momentos cabe entender que la penetración de las nuevas ideas en la corte española se produjo - entre otros factores - de la mano de una también renovada preocupación por las tierras ultramarinas españolas. Las necessidades políticas para América, cifradas en torno a la administración y el comercio transatlántico, plantea das por el Marqués de la Ensenada, ya habían sido expuestas por José del Campillo en su Nuevo sistema de gobierno para América, en 1743. Fernando VI y Ensenada, al configurar una política para la paz y una reflexión renovadora para la mejora del gobierno, crearon el clima necesario para que las "luces" se asentaran definitivamente en los asuntos públicos del imperio y para que la parte americana del mismo viera significativamente ligado su futuro a la impronta - tan revolucionaria como imperial - de las nuevas ideas y actitudes. Cuando Carlos III incorpore a las élites del poder de la monarquía a una generación educada en el arranque ilustrado, desliga da en lo posible de las tramas nobiliarias y eclesiásticas acrisola das por los Austrias, e imbuída del papel que correspondía a las Indias en la recuperación de la propia monarquía, el proceso antes apuntado se aquilata sin re- 
medio. Si a tales características se añade el h llazgo final de la institución militar como ámbito socio-político capaz de aislarse de los viejos estamentos, de garantizar por la obediencia la fidelidad a los proyectos de la corona, y de generar nuevas vías de movilidad social en el desempeño de las tareas burocráticas y de gobierno, es fácil colegir el calcance innovador -y perturbador a la vez - de esa legión de servidores del rey estusiasmada con las luces.

Las espectativas con que el reinado carolino se abrió para España y América se truncaron pronto verdaderamente, nada menos que con la irrupción de la Guerra de los Siete Años y sus desastrosos resultados para la alianza franco-española. Sin duda por esa frustración, los objetivos de la metrópoli española para con sus tierras americanas acabaron forzados en claves estratégicas, como luego veremos; pero aún así, las raíces ilustradas de las distintas fases reformistas pesaron de manera irreversible en América y en la propria España. Hay por tanto que preguntarse, al menos en el mismo tono ponderado, cuáles fueron y cómo se desenvolvieron esas ideas radicales. $\mathrm{O}$ lo que es lo mismo, cómo puede caracterizarse la Ilustración Hispánica.

\section{APROXIMACION A LA ILUSTRACION ESPAÑOLA}

La Ilustración española, que en este ensayo muy bien podría acotarse como Ilustración metropolitana o peninsular, encaja, tal y como he planteado antes, en la "segunda mitad" del siglo XVIII como muy bien nos ha explicado a todos el hispanista Jean Sarrailh. ${ }^{2}$ Pero no cabe simplificar esa perspectiva. En todo caso la "España Ilustrada" se corresponde con la élite cultural que en tiempos de Carlos III accedió en parte al poder y genéricamente a la "opinión pública" de la época. El historiador español A. Domínguez Ortiz ha advertido que es necesaria tal acotación, pero también abarcar la existencia de dos generaciones anteriores sin las cuales poco o nada puede comprenderse; se refiere al grupo llamado de los novadores y a la generación que media entre éstos y los tradicionalmente aceptados como ilustrados. ${ }^{3}$ A ese contexto que explica el desarrollo de la revolución científica de la España dieciochesca, hay que añadir otras dos perspectivas elementales: por un lado la proyección que tal desarrollo tiene en la formación de hombres e ideas que darán en llamarse liberales, cuyo brillo esencial se centra en el constitucionalismo de 1812 , y por otro la persistencia a lo largo de todo el siglo de una lógica reacción recalcitrante a las innovaciones ilustradas que - aunque acabará teñida también por corrientes filosóficas extranjeras - permite hablar con plena legitimidad de grupos y figuras tradicionales. Sólo así puede entenderse la existencia de una Ilustración española espe- 
cíficamente vinculada al reinado de Carlos III: en su contexto cultural y secular. E incluso, habría que delimitar claramente lo mucho que le debe esa Ilustración nuclear a los años de permisividad política y relajamiento de la censura propiciados por la corte misma, y que pueden acotarse entre 1760 e 1778 e poco más; ello explicaría tal vez - aunque no es éste el lugar para especular al respecto - la orientación hacia lo que conocemos por liberalismo de lo que fue previamente entusiasmo ilustrado.

De cualquier modo, y encaminados a establecer una idea básica de la Ilustración española, puede tenerse por cierta la existencia de dos pilares significativos de todo el proceso eideético peninsular. Son ellos las figuras señeras de Fr. Benito Jerónimo Feijóo y Gaspar Melchor de Jovellanos. Ambos creo que pueden tomarse como referencias capitales precisamente del arranque innovador y de la madurez ilustrada en España, respectivamente. Feijóo puede ser tenido, sin ningún tipo de reservas, por la primera conciencia intelectual que en la España del XVIII apela a la necesidad de renovación, ya fuese lamentando el atraso científico español - como lo había hecho antes Cabriada -, ya fustigando la funesta batahola de prejuicios y supersticiones que atan a los súbidos del primer Borbón hispano. Desde que el 3 de septiembre de 1726 la "Gazeta de Ma drid" anunciara la venta en la portería del Monasterio de San Martín del primer tomo del Teatro Crítico Universal, Feijóo pasó a ser la avanzada de una nueva era; el alto precio de aquel primer tomo - dos reales de a ocho - no impidió que los madrileños agotaran en poco tiempo la ediclón; igual sucedería con los siete volúmenes siguientes y con los cinco de las Cartas Erudidas; y es raro que el historiador americanista no conozca antes el precio - los distintos precios - del Teatro Crítico Universal, que los de otros productos de consumo más o menos generalizados, al acercarse a la segunda mital del siglo. Feijó, que escribió en los últimos años de su vida, supuso para peninsulares y americanos la llega da de un lenguaje próximo, cercano a todos los oídos, con el que acceder a cuestiones teológicas, históricas o médicas, despojado de erudición barroca pero cargado de sentido común. Probablemente aquel monje no fue un pensador genial, pero sí un revulsivo en la páramo intelectual del primer tercio del siglo XVIII español. Y el mero hecho de que se especule acerca de su paternidad sobre la generación ilustrada de tiempos de Carlos III, me parece prueba sobrada de la profunda significación de su obra para la Ilustración hispánica.

Melchor Gaspar de Jovellanos, en el extremo final de la Ilustración española, supuso la reflexión madura, característicamente optimista las más de las veces, en que desembocó la fructífera época carolina. Desde luego Jovellanos vivió un clima intelectualmente nutrido, y compartió la escena cultural española con hombres de la talla de Campomanes, Moratín, Cadal- 
so, Forner, Iriarte, Olavide o Meléndez Valdés. En la perspectiva que aquí he de trazar, cabe reconocer que Jovellanos fue ya un ilustrado básicamente español, peninsular, en la medida en que sus preocupaciones y disquisiciones estuvieron teñidas por una óptica política en la que América - las Provincias de Ultramar, ya para entonces - estaba delimitada en su papel netamente colonial. A partir de 1763 , y sobre todo después de la expulsión de los jesuítas, las Indias fueron tierras más a vigilar reorganizadamente que a promocionar de una forma integrada, como parecía vislumbrarse en el proyecto de transformarlas en reinos encabezados por príncipes españoles e integrados en un imperio de base federal, idea propia del tiempo de los novadores; por otra parte, no es difícil identificar el início de una Ilustración propiamente americana a partir de las fechas indicadas aproximadamente, y ello explicaría el hecho de que Jovellanos no tenga para los americanos una presencia asimilable a la de Feijóo. Jovellanos es más bien el paradigma del análisis ilustrado sobre la realidad española en su pasado y su presente, el representante más ajusta do de esa "apología crítica", característica de los intérpretes del despegue cultural español en tiempos de Carlos III, con respecto a las herencias y necesidades de su patria.

Por supuesto que entre Feijóo y Jovellanos, y sobre todo contemporáneamente al segundo, la Ilustración española cuenta con un amplísimo programa de objetivos científicos y culturales. Creo que si hubiera que acotar el sentido último de esa Ilustración, no habría más remedio que referirse a la idea de progreso. En tal sentido cabe entender todo lo que de universalista y a la vez doméstico tuvo la Ilustración en España. Y también en esa idea básica de progreso cabe encuadrar las acotaciones del professor Koch acerca de las esencias de la ilustración ibero-americana, que sintetizó en las cuatro siquientes:

- Aceptación de la investigación científica y sus resultados, con riesgo de chocar con creencias tra dicionales.

- Lucha contra la superstición, los "ídolos tribales" y los prejuicios irracionales, particularmente contra los que provocan la injusticia y la opresión.

- Una reconstrucción y revisión de las creencias básicas.

- Una dedicación a las obras de reforma social y económica. ${ }^{4}$

Esta síntesis me parece ajustada en un alto grado, ya que explica muchas de las ambigüedades que la Ilustración hispánica ha presentado. Ambigüedad procedente según creo de la coexistencia de una tensión aguda hacia la transformación política y un cambio social incompleto, desajustado, del que los propios intérpretes de la Ilustración fueron fieles y en ocasiones patéticos testigos. De ahí que la Ilustración hispánica hallara sus vías de manifestación más queridas en el ensayo programático de un lado y la fabu- 
lación un tanto burlesca, satírica frecuentemente, por otro; de ahí también la debilidad a la hora de defender el teatro de las furibumdas diatribas dirigidas contra él por el clero, pese al esfuerzo de Jovellanos en su memoria sobre Espectáculos y diversiones públicas, cuya primera versión data de 1790 .

De alguna manera cabe simbolizar los impulsos básicos de la Ilustración española - ya que no de toda la hispánica, que englobaría a la americana - en la imagen satírico-utópica que, atribuída con muchas, precauciones a Compomanes, probablemente fue escrita en el último tercio del siglo XVII. Me refiero a SINAPIA, la descripción anónima de una tierra utópica, opuesta en sus hipotéticas situación y esencias a la realidad española de la época. ${ }^{5}$ En Sinapia cabe identificar las claves del cartesianismo trasla dado por Feijóo al pensamiento hispánico, así como el perfil - que pudiera estar trazado por la reflexión de un novador tanto como de un ilustrado del conjunto de virtude sociales y políticas que, por oposición, detratan los vicios que en España impiden la salida final hacia el progreso ansiado. Así mismo en Sinapia pudiera detectarse la huella ineludible de la frustración que para la élite intelectual española supuso, no ya la muerte de Carlos III y el definitivo deterioro del clima político y cultural subsiguiente, sino incluso la etapa final del reinado carolino en la que se endurecieron las posturas antes tolerantes hacia la crítica ilustrada. Sinapia, me parece, bien puede tomarse como muestra clara tanto de las limitaciones patrióticas contempladas y sufridas por los últimos ilustrados como las de fines del XVII; al fin y al cabo, Sinapia eș una versión esperanzada de una frustración, pues en el otro extremo no hay mejor muestra de una culta desesperanza que las "pinturas negras" de Goya.

\section{AMERICA EN EL PENSAMIENTO ILUSTRADO ENPAÑOL}

Frecuentemente se ha querido caracterizar la actuación política de los gobernantes ilustrados de Carlos III con respecto a las Indias como una "reconquista" del continente americano. Creo que no puede darse con una versión más desnaturalizada de la realidad que ésa, pues cualquier parecido del periodo 1750-1800 en materia de política americana de España con la primera mitad del siglo XVI es pura retórica destinada a encubrir vacíos de comprensión. En todo caso, los ilustrados metropolitanos se limitaron a descubrir una América hasta entonces más obviada que ignorada, y ello a raíz del intento de recuperar el valor económico y estratégico de los reinos americanos, perdido desde aproximadamente 1610/20.

Precisamente ese valor estratégico de las Indias españolas en el contexto del imperio, puede tomarse como una perspectiva que explique algunos 
de los condicionamientos y resultados de la Ilustración iberoamericana. Ya antes aludí a las consecuencias de los resultados de la Guerra de los Siete Años, que cabe muy bien sintetizarlas en el efecto que la toma de La Habana por los británicos tuvo sobre la corte ilustrada de Carlos III. A partir de 1763/64 todo el esfuerzo político de España para con sus dominios americanos acabó centrándose en la necesidad de construir definitivamente una estructura imperial, antes de planificar o proyectar cualquier otro cambio sobre ellas, por deseado que hubiera sido hasta entonces para las propias autoridades metropolitanas. ${ }^{6}$

El primer resultado de ese giro político con respecto a la parte americana del imperio fue el envío de dos funcionarios con amplias competencias, e incluso gran capacidad de decisión, en calidad de visitadores a Nueva España y Perú. Es difícil dilucidar si José de Gálvez y José Antonio de Areche - los referidos visitadores - lograron más éxitos para la corona que resquemores e insidias para sus personas respectivas, durante sus estancias en Indias. Lo cierto es que Gálvez acabó convertido en el más alto y experimentado funcionario para Indias, hasta llegar a ser el ministro más significativamente reformista en la materia entre 1775 e 1787 . Globalmente, las consecuencias de sus actuaciones, cabe sintetizarlas en dos sentidos: por un lado el reforzamiento de las "fronteras bélicas" de Indias, ésto es, básicamente el Caribe, el Norte de Nueva España y más subsidiariamiente Paraguay, la Banda Oriental y Chile; por otra parte, el ejercicio de un control más firme de las "fronteras comerciales" de los domínios hispánicos en América, que primordialmente resultaron ser Buenos Aires, La Habana, las costas centroamericanas y Caracas; ésta última, considerada también como posible objetivo bélico, acabó reuniendo marcadamente los dos tratamientos por parte de la monarquía. Esta concepción global en doble sentido fue el origen de dos efectos capitales, normalmente emboscados en la compleja trama de medidas reformistas cuya sensatez ilustrada deslumbra en ocasiones al historiador: defender América impuso el arranque de la primera militarización sistemática de las Indias; controlar sus recursos y su comercio invitó sin remedio a un centralismo administrativo, bien remozado y tecnificado para su época. Toda la concepción halló su máxima expresión en el sistema de intendencias desde 1782 , que acabaría canalizando la integración socio-política de la mayoría de las élites locales y regionales de las Provincias de Ultramar, pero que también abrió la definitiva senda por la que una hegemonía militar y burocrática impondría taras singulares a la creación de los futuros estados latinoamericanos.

Si se medita sobre lo que acabo de sintetizar, no es difícil aritcular que la Ilustración hispano-americana contó al menos con dos etapas - antes y después de $1765 / 70$ - por lo que a proyección política se refiere, y con dos 
expresiones en gran medida divergentes a partir de esas fechas citadas: una Ilustración española y una Ilustración netamente americana que engloba diversas manifestaciones regionales peculiares.

Probablemente la mejor forma de articular el sentido de lo que acabo de exponer es seguir - siquiera someramente - la evolución del pensamiento económico ilustrado español con respecto a América. Esse pensamiento económico nació en la primera mitad del siglo XVIII básicamente como un conjunto de ideas sobre el comercio entre España y América, en función de las doctrinas fisiocráticas vertidas al caso por Jerónimo de Uztáriz, abundadas en esencia por Miguel de Zavala y Auñón y proyectadas al plano político por Bernardo de Ulloa en torno a $1740 .^{7}$ A partir de esa base, el pensamiento económico sobre el comercio con Ultramar permaneció atado a ciertos grandes problemas, cuales eran la decadencia interna de la economía peninsular y la necesidad de reactivarla. Si a ello se añade que hacia 1720/ 1740 España conoció el fracaso definitivo del tradicional sistema de flotas y galeones, ${ }^{8}$ imposible ya de reestructurar, puede comprenderse que en el largo periodo de génesis de las reformas definitivas se sentaran dos principios elementales con respecto a América: fomentar su desarrollo económico y establecer una vía de control absoluto del suculento comercio que ello habría de procurar. Para tales objetivos existieron dos magnos proyectos políticos: el uno fue el de tratar de establecer un liderazgo indiscutible de la Península respecto de los reinos indianos, con las anteriormente mencionadas características federales; evidentemente aquello fue imposible, por meras limitaciones materiales; la otra posibilidad era - y fue - imitar o adaptar las experiencias extranjeras, sobre todo francesa y británica en el Caribe y las Trece Colonias, y combinar la apertura hacia la liberalización comercial con el ejercicio de un poder fuertemente centralizado. En esta última vía parecieron cumplir un papel capital las Sociedades Económicas y las Compañías de Comercio, pero si las primeras languidecieron lentamente sin perder en ningún momento su carácter de extravagante intromisión peninsular, las segundas apenas si se hurtaron a la fácil tentación de reproducir las "flotas y galeones" con criterios focalistas, cuando no se limitaron al simple desempaño como intermediarias en los contextos comerciales dominados desde mercados extranjeros. ${ }^{9}$

Fue con toda probabilidad el pensamiento ya marcadamente mercantilista de Merchor de Macanaz el que introdujo una variante capital: las Indias debían primordialmente abastecer a su metrópoli de oro y plata, para lo cual nada mejor que consumieran manufacturas españolas y no de otras potencias europeas. Esa idea, tan sintéticamente aquí expresada, encajó mejor que ninguna otra complicación acerca de la utilidad de los impuestos manifestada hasta entonces, especialmente cuando la monarquía ilustrada 
trataba también de integrar la capacidad productora de los reinos peninsulares. Añádanse las ideas sobre la Hacienda Real del Marqués de la Ensena da y algunos de los avisos de José Campillo y Cossió, y ya se tiene perfilada la doctrina económica que desemboca en el centralismo administrativo y la libertad de comercio a partir de 1775 , pero que estuvo apuntada desde 1762 en el Proyecto Económico de Bernardo Ward. Las ideas económicas más tardías de Romá y Rosell, Valentín de Foronda, Cabarrús, el propio Jovellanos, Floridablanca, Campomanes o Larruga, poco más aportaron de nuevo, llegando a alcanzar esta línea de pensamiento incluso a Alvaro Flórez Estrada. Por donde quiera que se mire, no cupo al despotismo ilustrado de Carlos III mejor doctrina sobre el comercio con Indias que aquella que convertía, de una vez por todas, a sua reinos de América en auténticas colonias. ${ }^{10}$

Todo eso, claro está, tropezaba con una realidad: la disposicón al respecto de los "españoles de América", a los que muy pronto se les comenzó a llamar definitivamente "criollos", y que desde más o menos 1580 sabían mejor que nadie qué les interesaba a ellos y cómo hacerlo, qué se le podía ocurrir a la corona y cómo eludirlo o volverlo en su favor diplomáticamente.

Entre 1775 y 1787 las intenciones metropolitanas de España para con sus Provincias de Ultramar alcanzaron el grado más alto de realización. Entre esas fechas no sólo fraguaron las principales reformas territoriales de origen estratégico, ni tampoco pararon las medidas transformadoras en la de por sí fundamental aplicación de las Ordenanza de Intendentes. En esa época tomaron cuerpo definitivamente algunas ideas sobre control minero y mercantil de capital transcendencia, cimientos de los tribunales de mineria, bancos de rescate, bancos de avio y compañias de aviadores, instituciones todas de gran relevancia para el futuro económico de las también futuras naciones independientes. Otro tanto cabe decir de la multiplicación, con un peculiar criterio regional, de nuevas audiencias, así como de la extensión de servicios básicos para el transporte, renovación de caminos e instauración de correos, materias en las que intendentes marcadamente ilustrados tuvieron mucho que ver y que decidir. ${ }^{11}$

Tantas mejoras como pueden enumerarse, y no precisamente construidas en el aire, tuvieron para los súbditos americanos de Carlos III una contrapartida primordialmente fiscal de compleja y renovada extensión en la que no cabe ahora entrar. Antes y durante lo más nutrido de la actuación de los nuevos funcionarios ilustrados enviados desde la metrópoli $-\mathrm{y}$ de los que se puede afirmar que generalmente fueron competentes - la España ilustrada procedió a un descubrimiento, o redescubrimiento, táctico de sus tierras americanas. Me refiero con ello a la frecuencia con que la España del XVIII se ocupó y preocupó de las Indias, precisamente con un sentido 
muy acusadamente ilustrado. Si habían de ser tierras rentables, propiciar un jugoso comercio con la península, y agotar los géneros que ésta tuviera a bien enviarles, era necesario conocer bien aquellos mercados, sus capacidades reales y sus vicios de antaño y del momento mismo.

Desde que Antonio de Ulloa y Jorge Juan levantaron con sus Noticias Secretas el telón del teatro de las verdades y una parte de las mismas fueron conocidas en España, raro fue el funcionario que no tuvo por deber patriótico el repetir, en la medida de sua posibilidades y su destino, la hazaña informadora; hasta el punto de que tal misión fue una de las especialmente encomendada a los intendentes en sus Ordenanzas.

Conocer bien América tuvo un doble sentido: contar con medios para gobernarla mejor y a la vez reorganizar la artillería erudita para hacer frente a las infamias de la "Leyenda Negra". ${ }^{12}$ De hecho, si los ilustrados de Carlos III querían ajustar bien el papel económico y estratégico de las Indias, se hacía imprescindible levantar una "leyenda blanca" en torno al dominio español. El Diccionario Geográfico-Histórico de las Indias Occidentales o América, publicado en Madrid entre 1786 y 1789 por Antonio de Alcedo, así como la gran acogida que tuvo entre lectores de España y Ultramar, es posiblemente la mejor prueba de lo señalado. Los informes y escritos de Félix de Azara, durante sus veinte años de permanencia en el Río de la Plata, pueden situarse en la misma línea, con la virtud añadida de estar cargados de un sentido crítico de la realidad española en América que dobla el valor de la obra y la talla ilustrada del autor. Más universalmente reconocido, Celestino Mutis alcanzó las cotas más altas de la ciencia ilustrada y sus informes sobre la minería neogranadina para la Secretaría de Indias son piezas aún hoy día de incalculable valor.

A una posible "leyenda blanca", pero no a la defensa de la presencia española en Indias precisamente, cooperaron de una forma especial los escritos de los jesuítas expulsos, en los que a veces la realidad de añoradas tierras cobraron vuelos sospechosamente ex́celsos. Los más destacados de ellos, como Clavigero, Alegre o Andrés Cavo entre otros, pusieron sus ojos en América casi exclusivamente; pero no faltó de entre las filas ex-jesuíticas quien hiciera frente a las "calumnias" vertidas sobre la América española por De Pauw, Raynal o el reverendo Robertson: las Reflexiones imparciales sobre la humanidad de los españoles en las Indias contra los pretendidos Filósofos y Politicos..., de Juan Nuix y Perpiñá, publicada en Venecia en 1780; traducida al español dos años después y al francés en 1788, me parece una muestra fundamental de la existencia de una conciencia ilustrada en los ámbitos hispánicos encaminada al conocimiento científico riguroso de la realidad americana. Ni que decir tiene que el abate Nuix fue considerado por Sempere y Guarinos como una figura señera de la Ilustración española, olvi- 
dando su condición de ex-jesuíta, e incluyéndolo en su Ensayo de una biblioteca de los mejores escritores del reinado de Carlos III, de 1786. Pero para esas fechas la Ilustración española y su visión de América se puede decir que sufría las consecuencias del afán político que en gran medida lo había suscitado. Quizá hacia 1785 el conocimiento español de América prescindía muy a menudo de algo que aquí nos interesa especialmente: la Ilustración Iberoamericana, propiamente dicha.

\section{LOS FUNDAMENTOS DE LA ILUSTRACION EN LA AMERICA ESPAÑOLA}

Es comprensible que la Ilustración iberoamericana fuera deudora básicamente de la española. Ante todo porque las ideas y escritos procedentes de Francia, Inglaterra o Alemania, llegaron a contados habitantes de las Indias; pero también porque la ofensiva ilustrada de España sobre sus colonias americanas fue amplia y específica, como he tratado de señalar hasta ahora. Aparte de esta razón elemental, hay que tener presente que el "imperio de la razón" no era precisạmente un principio ajeno al pensamiento hispánico anterior al siglo de las Luces, y que de hecho figuras señeras como Fernández de Oviedo, el padre Las Casas, Vitoria y los más tardíos Solórzano y Sigüenza y Góngora, entre otros, significaban una tradición fuertemente racionalista en la comprensión y concepción de la realidad. En esa línea hay que encajar el que la Ilustración de In dias fuera, como la española, una innovación dentro de cauces ortodoxos, una Ilustración cristiana, en fin. No debe olvidarse que un esfuerzo habitual en los colegios jesuíticos del XVIII americano, así como en algunos círculos franciscanos más tarde, fue el de despojar de herejías a Descartes, para tomar todo lo positivo que se reconocía en su duda metódica. Como a las españolas también, a las Luces de América no les faltó el necesario ribete anticlerical - en lo que tanto tuvo que ver Feijóo -, y de hecho si algo hay característico de la Ilustración iberoamericana es el haber servido a un muy ajustado proceso de secularización de sus sociedades. Otra cuestión significativa - y que es necesario recordar es que la Ilustración no afectó a las masas de América, sino a élites reducidas, unas con claro espíritu asimilador de las novedades - las más citadas y reconocidas, tal vez -, otras reacias y disconformes con cualquier cambio que amenazara lo más mínimo a su estatus - y éstas fueron frecuentemente las más poderoras y decisivas -. En la medida en que la Ilustración, en su versión española, llegó a Indias en clave de reformas, hay que referirse a los desórdenes de Quito de 1765, o los de Nueva España de 1767/69 - tan directamente dirigidos contra el visitador Gálvez -, o a la revuelta comunera 
de Nueva Granada en 1781, e incluso a la conspiración en la Venezuela de 1795 , para entender lo mucho que de "movimiento a la contra" tuvo la Ilustración en las colonias de España. Y, en fin, también hay que advertir que lo más florido del pensamiento ilustrado iberoamericano arrancó con la independencia y fraguó en la construcción del estado independiente, aunque a los historiadores nos guste a veces vestirlo de prerromanticismo y mucho haya de ello en efecto. Por debajo de estas bases genéricas apuntadas, hay que contar con las marcadas peculiaridades regionales de la América del XVIII, lo que supone que la recepción de ideas no fue idéntica en todas partes y por tanto que sus resultados también difieren a veces ra dicalmente.

Prácticamente a poco de que en 1735 lleguen a Indias las obras del padre Feijóo, se sabe de la introducción en colegios jesuíticos de las ideas de Descartes, Newton, Leibniz, etc., como frente elemental ante el imperio del escolasticismo. Es indudable que en esa circunstancia pesó de manera firme el avance tecnológico en la navegación, que permitió la puntual llegada de las publicaciones europeas en plazos relativa $-\mathrm{y}$ a veces sorprendentemente - breves a América. Hacia 1760 son abundantes las noticias de bibliotecas particulares bien abastecidas, $y$ en todo momento parece que fueron inútiles los esfuerzos inquisitoriales por hacer valer el espíritu de los índices cada vez más frecuentes y extensos; posiblemente, porque los libros prohibidos llegaban a menudo en las valijas de los nuevos funcionarios procedentes de la metrópoli y porque parte sustancial del reinado de Carlos III logró quebrar la omnipresencia inquisitorial. Para 1775 el número de imprentas en el continente había salido de la precaria casuística tradicional hasta entonces, y es rara la capital ultramarina que en las dos últimas décadas del XVIII no contó con ese medio primor dial. Las Gazetas, tímidamente aparecidas hacia 1670, irrumpen desde 1784 con la "Gaceta de México", a la que siguen el "Papel Periódico" de La Habana, el "Mercurio Peruano", el "Semanario del Nuevo Reino de Granada", las "Primicias de la Cultura de Quito", o el "Telégrafo Mercantil" de Buenos Aires, por citar los más destacados o siquiera los de más larga y fructífera vida.

Aspecto fundamental de la Ilustración iberoamericana es sin lugar a dudas la relación que ésta tuvo con los medios eclesiásticos. Antes me refería a la existencia de una huella anticlerical entre los medios ilustrados de América que es cierta, pero que debe acotarse en su contexto, por cuanto fue el resultado de una de las principales acciones del gobierno metropolitano encaminada a desarticular cualquier tipo de organización capaz de deteriorar la actuación del estado. Paralelamente a ello, es evidente que el clero de las colonias españolas en América jugó un papel sustancial en el progreso ilustrado de tales regiones. Hay que tener en cuenta al respecto que para enjuiciar debidamente al clero americano del siglo XVIII de be partirse, 
en primer lugar, de un conocimiento del papel socio-político juga do en la formación de las distintas soçiedades criollas, terreno en el que aún no contamos, a mi juicio, con estudios suficientes y actualizados; para esa perspectiva, y en segundo lugar, los problemas historiográficos sobre ese clero americano nacen más de su emplazamiento social que de la mera definición o acotación teológico-institucional; y abundan do en ésto, debe tenerse presente que la filiación regular pesó tanto o más que el encuadramiento jerárquico eclesial. Sobre esta base, es útil todavía recordar las dos importantes cuestiones que, según Karl Schmitt, dividieron al clero americano en el siglo XVIII: regalismo frente a ultramontanismo y derecho divino de la monarquía frente a constitucionalismo. ${ }^{13}$

Con tales supuestos procede un mejor discernimiento sobre la diversidad de resultados intelectuales de origen eclesiástico en el XVIII americano, dentro de una tendencia general hacia la apertura a las novedades del siglo. El problema no es estrictamente la actitud de determinados miembros del clero hispanoamericano ante la perspectiva emancipadora, sino la posición socio-política que ocupan ante ese trance. Así, por ejemplo, debe encararse el comportamiento de Manuel Abad y Queipo - obispo electo de Michoacán - al combinar su fe en las reformas económicas y sociales con la defensa de la causa realista; en Buenos Aires puede observarse igualmente el comportamiento contradictorio de diferentes clérigos ante el estallido emancipador, así como en Quito o Puebla, por citar los casos más conocidos. En ocasiones, tales circunstancias llevan a cuestionar la etiqueta de "ilustrados", pero creo que eso es resultado de una mera especulación que acaba ocultando la realidad. No debe olvidarse que fueron clérigos José Antonio Alzate, José Celestino Mutis o Gregorio Funes, ni tampoco los impulsos reformadores del arzobispo Caballero Góngora en Bogotá y del obispo José Antonio de San Alberto en Córdoba. El clero en fin, como amplio estamento tradicionalmente vinculado a la enseñanza y la especulación teológica y científica, y con acceso más inmediato al cultivo del espíritu, fue lógicamente directo receptor de las novedades ilustradas; si a ello se añade la posición netamente definidora del ordenamiento social $\mathrm{y}$, específicamente en América, étnico, no hay que admirarse de lo imbricado de su protagonismo.

Lo que sí me parece que detentará durante algún tiempo aún características de polémica es el significado que para la Ilustración iberoamericana, y su historia en general, alcanzó la expulsión de la Compañía de Jesús. Como introductores, según ya se ha señalado, de las ideas renovadoras en distintos ámbitos americanos el impacto de la medida metropolitana estuvo asegurado, a nivel social como intelectual. Pero es posible considerar incluso el año 1768 como una frontera en la orientación de las Luces americanas. 
A grandes rasgos, la aceptación del extrañamiento por las altas jerarquías de la Iglesia en América enmarañó gran parte de las cuestiones sobre el regalismo, que habían heredado de la polémica "jansenista"; y, a grandes rasgos también - como apuntó Schmitt -, tanto los jesuítas como los obispos podrían ser clasificados como "anti-ilustrados" en sus respectivas posiciones de ultramontanistas y partidarios del derecho divino de la monarquía. Esa acotación me parece del todo correcta. Pero piénsese que los jesuítas expulsos encendieron la antorcha de la vindicación de América; y no cabe duda que Viscardo, Clavigero, Andrés Cavo o Alegre, pusieron el acento americano precisamente cuando la metrópoli empezaba a pretender domesticarlo. En fin, creo que la cuestión sobre la influencia jesuítica y de la expulsión misma puede orientarse en un sentido positivo: por un lado para considerar que a partir de 1768 puede hablarse del arranque de una Ilustración hispánica alternativa a la de España, proceso en el que el periodo 1775-87 - de intensas reformas - tendría más relevancia incluso que la propia expulsión; por otra parte, cabe tomar el papel jugado por la Compañía de Jesús respecto a América como el catalizador hacia una mayor peculiarización de las distintas versiones americanas del movimiento ilustrado.

\section{IBEROAMERICA ILUSTRADA:}

\section{LAS ALTERNATIVAS CRIOLLAS}

Volveré a insistir en que hasta 1775 básicamente la Ilustración no alcanza las cotas más deslumbrantes en las colonias españolas de América. Uno de los fenómenos más llamativos en los que se puede detectar esa realidad es la forma y la extensión con que se trasladaron al Nuevo Mundo las "Socie dades Económicas de Amigos del País", en cuanto modelo que tanto juego había dado al reformismo en la península. Entre 1781 y 1819 llegaron a existir quince de tales "sociedades" en América con una curiosa, genérica y significativa vida. Transplantadas con el mayor beneplácito de la corona, acabaron siendo consideradas frecuentemente como peligrosos núcleos innovadores, a pesar de la languidez con que la práctica totalidad se desarrollaron. En realidad, y pese a las sospechas de ciertos grupos conservadores entre los que abundaron los eclesiásticos, el modelo anglo-francés de societies of arts que obtuvo una acogida favorable en España no contó con las preferencias criollas. Sobre la base de la tertulia - arraiga da institución más espontánea -, en los ámbitos indianos contó con más favor la posibilidad de otorgar un particularismo específico al intercambio de ideas a puerta cerrada; si se quiere, valdría más hablar de club e incluso de sociedad secreta, si se trata de generalizar sobre los gustos criollos ilustrados. Ese tipo de reu- 
nión exclusivista, en la que la identidad criolla podía defenderse de la arrogancia mostrada por los nuevos funcionarios recién llegados y poseídos de la relevancia de su cargo, encajó mejor en los a menudo imparables procesos de integración socio-regional. ${ }^{14}$

$\mathrm{Si}$ a través del gregarismo más o menos científico típico de la Ilustración cabe detectar la presencia de alternativas criollas, no menos sucede al repasar el panorama de las instituciones efectivamente vinculadas a la ciencia. La actualización de los planes de estudios de distintas universidades iberoamericanas fue el arranque de un nuevo clima intelectual. Desde 1768 México contó con una Facultad de Medicina y desde 1788 con un Jardín Botánico; el Observatorio Astronómico de Bogotá, la Escuela Naútica de Buenos Aires, la Academia de Bellas Artes mexicana, se sumaron a las veintiseis instituciones con prerrogativas univerșitarias existentes en el siglo, a la hora de irradiar nuevas ideas y actitudees. En tal sentido, la reforma carolina de 1771 sobre la función de los colegios significó la apertura de una nueva vía para algunas regiones americanas hasta entonces marginadas o desasistidas. La obra paciente de los jesuítas hasta el momento de su expulsión ençontró continuación las más de las veces en franciscanos y dominicos, a la hora de hacerse cargo de cátedras, colegios y bibliotecas; no fal tó tampoco la continuación del interés por la producción de obras científicas renovadoras, sin duda desde la misma adaptación "ecléctica" de las innovaciones ensayadas por los jesuítas, como es el caso del tratado de física del franciscano Cayetano Rodríguez, aparecido en 1796, o de los Elementos de Filosofia Moderna del padre Juan Gamarra, publicados en 1774.

Con todo y todo, el XVIII americano fue más un siglo de individualidades intelectuales que de instituciones universitarias. El esfuerzo de ciertas personalidades por romper el aislamiento en que se desenvolvieron a menudo, explica la admiración de algunos extranjeros participantes en expediciones científicas y, por vía de ejemplo, el interés de Linneo por conocer los trabajos de Mutis. En la misma perspectiva debe situarse a Baquijano, Villava, Arango y Parreño, Azzara, Caldas, Simón Rodríguez, Alzate, Gama, Velázquez o Funes.

Los resultados de las intervenciones de hombres e instituciones bien puede significarse en el interés por obtener una base de renovación de la sociedad criolla, centrada en la generalización y perfeccionamiento de la enseñanza. Especialmente en México y Caracas la Ilustración puso el acento en la renovaciọn de las escuelas de primeras letras, así como en la modernización de las instituciones que facilitaban el camino hacia los estudios universitarios. Fue ese un terreno en el que el camino hacia la secularización quedó patentemente marcado con la aparición de escuelas públicas como alternativa a las pias, con la acusada vinculación de la enseñanza primaria a los in- 
tereses de los cabildos municipales criollos, y con el esfuerzo - ya a comienzos del siglo XIX y sobre todo tras la independencia - por implantar el método lancasteriano, el sistema de pasantes, etc. La supresión, o conversión mejor, del gremio de maestros de primeras letras en Madrid en 1780, sirvió de base y estímulo para que Caracas y México incorporasen a su reordenamiento urbano una distribución racional de las escuelas; la educación femenina fue objeto de especial atención por parte de eclesiásticos y seglares criollos, en una carrera por desvincularla de la mera reclusión conventual. Simón Rodríguez y Miguel José Sanz, ambos venezolanos, pueden ser tenidos por auténticos transformadores de la enseñanza primaria en el mundo hispánico; e imbuído por las ideas especialmente del primero, Simón Bolívar llevó la idea, el método y aún al propio creador del sistema lancasteriano a las tierras americanas.

En una visión tan apretada, en la que he tratado de sintetizar las estructuras y significados de la Ilustración española e iberoamericana, no creo que quepa aludir al clásico problema de la relación entre la Ilustración y la Independencia. De alguna forma, esas fueron dos realidades distintas pero inseparables. Valga pues un único reflejo del pensamiento de Flórez Estrada - español, ilustrado, liberal exiliado en Londres e impotente observador de la escisión hispano/americana -, como botón de muestra de una conciencia histórica y política generada por las Luces, ya para 1811:

“...Si la América unida a la España debiese en lo sucesivo ser tan infeliz como lo fue desde su descubrimiento, sería de apetecer que jamás lo hubiese estado. Si la España no hubiese de sacar más ventajas de la posesión de la América, que las que sacó hasta aquí, sería un bien para ésta perder su posesión. Si la América no ha de producir a la Europa otras utilidades que las que hasta aquí, sería una locura felicitarse de su descubrimiento..."

Tan amarga reflexión como la de Flórez Estra da creo que debe ser empleada en una coyuntura eideética singular: la ilustración política que explica los diferentes procesos emancipadores tuvo sus fuentes primordiales en la articulación de la independencia de las Trece Colonias. Los restos escolásticos, la influencia francesa o los debates del primer liberalismo peninsular, tal vez no fueron sino los lenguajes en que fueron vertidos el espíritu de Filadelfia, los artículos de confe deración, la Constitución del 87 y el liderazgo político e intelectual de Washington y Franklin. Al fin y al cabo la búsqueda de la peculiaridad local, regional y continental proporcionada por las "Luces" a las Américas hispánicas, sintonizó mejor con los resultados de la ruptura colonial acaecida en el norte que con las especualciones de procedencia metropolitana, a la hora de lograr la propia emancipación. 
La tarea transcriptora de Manuel García de Sena, o la labor inflamatoria de fray Servando Teresa de Mier, tuvieron mucho más que ver en el laboreo del mar por Simón Bolívar que la prédica erudita del liberalismo reunido en Cádiz.

\section{NOTAS}

${ }^{1}$ Charles Marazé, La lógica de la historia. Madrid, 1970. (cap. 4 passim).

2 Jean Sarrailh, La España ilustrada de la segunda mitad del siglo XVIII. México-Madrid, 1974 (1 a reimpr.).

${ }^{3}$ Antonio Domínguez Ortiz, Sociedad y estado en el siglo XVIII español. Barcelona, 1976 (caps. 6 y 7 passim.). Otro enfoque clásico, Richard Herr, España y la revolución del siglo XVIII. Madrid, 1975 (3 a reimpr.).

${ }^{4}$ A. Owen Aldridge, The Ibero-American Enlightenment. Chicago - Londres, 1971. Pág. 8.

${ }^{5}$ Sinapia. Una utopía española del siglo de las luces. (Edición de Miguel Avilés). Madrid, 1976; Stelio Cro, Sinapia. A classical utopia of Spain. Hamilton, 1975. Avilés, en la pág. 65 de su edición, aventura la autoría de Campomanes sin darla por rotundamente cierta, aunque da por fecha el último tercio del XVIII. Cro es quien analiza más extensamente el problema y opta por el último tercio del XVII.

${ }^{6}$ Dos enfoques recientes para la comprensión genérica del problema aludido en Peggy K. Liss, Atlantic Empires. The Network of Trade and Revolution 17131826 . Baltimore and London, 1983; y Tulio Halperin Donghi, Reforma y disolución de los imperios ibéricos. 1750-1850. Madrid, 1985.

${ }^{7} \mathrm{Al}$ respecto, Marcelo Bitar Letayf, Los economistas españoles del siglo XVIII y sus ideas sobre el comercio con las Indias. México, 1975.

${ }^{8}$ Geoffrey Walker, Política española y comercio colonial. 1700-1 789. Barcelona, 1979.

${ }^{9}$ R.J. Shafer, The Economic Societies in the Spanish World (1763-1821). Syracusa, 1928 (Hay reedición posterior de 1958). Antonio García-Baquero, Cádiz y el Atlántico, $1717-1778.2$ vols. Sevilla, 1976.

10 J. Fisher, “Imperial 'Free Trade' and the Hispanic Economy, 1778-1796", The Journal of Latin American Studies. XIII, 1. (1982): P.K. Liss. op.cit.

$11_{\mathrm{Al}}$ respecto las obras clásicas de John Lynch, Administración colonial española. 1782-1810. Buenos Aires, 1967 (2. ed.); J.R. Fisher, Gobierno y Sociedad en el Perú Colonial el régimen de las Intendencias, 1784-1814. Lima, 1981. Es muy útil el breve ensayo de W. Borah, "Las ciudades latinoamericanas en el siglo XVIII: un esbozo", en El proceso de urbanización en las Américas desde sus origenes hasta nuestros días. México, s.a.

12 Antonello Gerbi, La disputa del Nuevo Mundo. Historia de una polémica, 1750. 1900. México, 1960; Paul J. Hanben, "White Legend Against Black: Nationalism and Enlightenment in a Spanish Context', The Americas, XXXIV, 1 (1977); José Carlos Chiaramente, La crítica ilustrada de la realidad. Economía y sociedad en el pensamiento argentino e iberoamericano del siglo XVIII. Buenos Aires, 1982. 
${ }^{13}$ Karl Schmitt, "The Clergy and the Enlightenment in La tin America: An Analysis". The Americas, XV, 4 (1959). En el mismo número: John T. Lannign, "The Church and the Enlightenment in the Universities".

${ }^{14}$ R.J. Shafer, op. cit.; sobre la pujanza de las logias masónicas, desde la perspectiva emancipadora, Harold D. Sims, La expulsión de los españoles de México (1821-1828), Madrid, 1974; un estudio específico con planteamientos reveladores y explicativos en Alfonso Fernández Cabrelli, Masonerí, Morenismo, Artiguismo. Montevideo, 1982. 15 Alvaro Flórez Estrada, Examen imparcial de las disensiones de la América con la España, 1811, pág. 161.

*Este ensayo tiene su origen en la conferencia sobre el mismo tema pronunciada en el "Colloque International sur le Monde, les Idées et l'Ouvre de Simón Bolívar", organizado por la Delegación Permanente de Venezuela ante la UNESCO y celebrado en París en Junio de 1983.

** Universidad Complutense Sección de Historia de América Madrid. 